\title{
Regional bedrock geochemistry associated with podoconiosis evaluated by multivariate analysis
}

\author{
Jamey N. Cooper (iD) Allen M. Cooper (D) Benjamin L. Clausen (D) \\ Kevin E. Nick (1)
}

Received: 13 February 2018/ Accepted: 20 July 2018/Published online: 5 September 2018

(C) The Author(s) 2018

\begin{abstract}
Podoconiosis is a disease whose etiology remains murky. Currently, the disease is attributed to particles that are believed to move through the skin and into the lymphatic system causing swelling of the lower legs. Identity of these particles or their composition remains unclear, though the presence of silicon and/or aluminum is often noted and frequently cited as causal agents. We applied multivariate analyses to the bedrock compositions of a large set of cases from an online database in an effort to identify underlying patterns or combinations of relative element abundances associated with podoconiosis-endemic regions. Using a combination of principal component analysis, discriminant function analysis, and ANOVA, we analyzed ten oxides from five regions on the African continent known to be associated with podoconiosis. The Hawaiian Islands were included as a control group since they are not known to have cases of podoconiosis
\end{abstract}

Electronic supplementary material The online version of this article (https://doi.org/10.1007/s10653-018-0158-0) contains supplementary material, which is available to authorized users.

J. N. Cooper $(\square)$. A. M. Cooper .

B. L. Clausen · K. E. Nick

Department of Earth and Biological Sciences, Loma

Linda University, Loma Linda, CA 92350, USA

e-mail: jhiday@1lu.edu

\section{B. L. Clausen}

Geoscience Research Institute, Loma Linda, CA 92350, USA despite similarity in geology and agricultural practices. Our analyses suggest that a unique alkaline- and silicon-rich geochemistry underlies regions associated with podoconiosis. Our results also imply that minerals enriched in incompatible elements, such as $\mathrm{Ca}, \mathrm{K}$, $\mathrm{Mg}$, and $\mathrm{Na}$, may be stronger predictors of the presence of the disease than either silicon or aluminum.

Keywords Podoconiosis - Rift volcanics - Principal component analysis - Multivariate analysis .

Geochemistry

\section{Introduction}

One of the greatest challenges in many areas of research is uncovering meaningful patterns and relationships within large, complex data sets. Multivariate statistical analyses are valuable tools for probing such data sets, allowing investigators to, among other things, identify underlying structure present in a set of variables, as with principal component analysis (PCA), and classify subjects into groups, as with discriminant function analysis (DFA). The use of these methods is not new to geology. Bisani et al. (1983) analyzed 11 major and 13 trace elements related to igneous rock composition from five islands in the Aeolian Archipelago using PCA and found that the 
islands could be distinguished from one another based on four components. They also found the results supported process models of rock formation. Similarly, Grunsky et al. (1992) used PCA to reduce the number of dimensions required to identify a particular magma group. Le Maitre (1976) used DFA to classify rock samples into either basalts, andesites, dacites, or rhyolites using their major oxide composition. $\mathrm{He}$ believed this method could be a satisfactory way to relate the chemistry of a rock to its mineralogical classification in a more quantitative way. Pearce (1976) successfully employed DFA to classify various types of basalts. A very convincing use of multivariate methods for geological interpretation was Ragland et al. (1997) methodical use of both PCA and DFA to analyze the Martinsville igneous complex. Comparing the results of multivariate analyses to more traditional geological approaches, they found that not only did the multivariate approaches group and classify the data the same as more traditional approaches but they also retained and portrayed the petrogenic significance of several mineralogical groupings such as mixing and control line populations. We employed this approach to look for distinguishing characteristics of regions known to have podoconiosis.

Multivariate analyses are especially valuable for analyzing large data sets such as are available from GEOROC (http://georoc.mpch-mainz.gwdg.de/ georoc/), NAVDAT (www.navdat.org), National Geochemical Database (https://mrdata.usgs.gov/ ngdb/rock/), or EarthChem (http://ecp.iedadata.org/). Access to these large bodies of data allows researchers to look for underlying trends that might not be apparent in smaller data sets collected by single individuals. The global nature of these data provides the potential for comparisons not only regionally, but across continents. In addition, these databases provide access to data from regions to which a researcher may not be able to travel due to budget, time, or political constraints. Of course, the real benefits to using large data sets are the sheer number of samples that can be analyzed. Patterns that would have been hidden when analyzing dozens of samples become visible when thousands of data points are included.

Podoconiosis is a little-known disease that causes swelling and disfiguration of the lower legs. Podoconiosis occurs in several developing countries where shoes are not worn on a regular basis. Worldwide, podoconiosis affects about four million people in at least 34 countries, with major areas of incidence in Africa, South America, and the Indian subcontinent (Loewenthal 1934; Clark 1948; Jordan et al. 1956; Cohen 1960; Price 1975, 1990; Price and Henderson 1981; Price and Bailey 1984; Corachan et al. 1988; Ruiz et al. 1994). Ethiopia has the unfortunate distinction of being the country most highly affected, with recent geostatistical modeling estimates of 1,539,963 affected individuals in 2015 (Deribe et al. 2017). The etiology of podoconiosis is still unclear, but as far back as the 1800s a correlation between podoconiosis and the environment led to many theories that the soil and a subcomponent were causative agents. The association between volcanic soils and agricultural communities in which footwear is often a luxury strengthened the mineral-related hypothesis. Through daily work in agricultural fields, individuals' bare feet are in constant contact with the soil, and thus with the particles believed to induce podoconiosis (Price and Bailey 1984). However, epidemiological work over the years has shown the disease to be highly localized (Oomen 1969; Price 1974b; Deribe et al. 2013, 2017). This suggests enrichment of a particular component either due to either a specific bedrock geochemistry underlying endemic locations and/or unique weathering patterns during soil formation.

During the 1970s and 1980s, the physician Ernest Price believed he had narrowed down the cause to a "tropical red soil," classified as ultisol or ferrosol, formed through the weathering of alkalic volcanic rocks (Price 1974b, 1976). Price and his colleagues sought to determine whether this association between soil and disease was one that could be demonstrated within the body. They studied the lymph nodes of patients living in affected and unaffected regions and found particles containing silicon, aluminum, and iron inside the nodes of both groups of patients (Heather and Price 1972). Having established the presence of particles within the lymph system, the authors tried to determine whether a difference in the quantity of particles existed between diseased patients and those not exhibiting symptoms. Price and Henderson (1978) suggested that more birefringent particles, interpreted as inorganic particles, were found in diseased patients, but were unable to establish whether elephantiasic nodes contained more total particles than the nonelephantiasic. In a later paper, Price and Henderson (1979) did, however, report a difference in the 
numerical distribution of particles exhibiting various $\mathrm{Al} / \mathrm{Si}$ ratios between diseased patients and those not exhibiting symptoms. Further work also revealed higher numbers of submicron-sized clay particles, specifically kaolinite, in the disease-associated soils (Price and Bailey 1984). A summary model proposes that weathering of source rock leads to the formation of clay-rich soils, and that fine, clay-sized particles are the source of the irritating nature of the soil (Price and Henderson 1979; Price et al. 1981; Price and Bailey 1984). More recent work by Molla et al. (2014) reports no significant association with particle size, but did find smectite, quartz, and mica to display positive correlations. Le Blond et al. (2017) report a higher volume $\%$ of fine particles in endemic soils as well as higher amounts of $\mathrm{Al}_{2} \mathrm{O}_{3}, \mathrm{Cr}$, kaolinite, mica, $\mathrm{Ni}$, quartz, $\mathrm{SiO}_{2}$, Y, and $\mathrm{Zr}$.

Several factors play a role in the formation of soils including parent material (bedrock), climate, organisms, relief, and time (White 2013). This process becomes infinitely more complex as each of these factors may change over time leading to different factors playing the dominant role in pedogenesis. In an effort to more fully understand the origins of podoconiosis, each of these factors must be examined individually. Previous podoconiosis research has investigated both climate, identifying modern cases to be limited to tropical environments, and relief, correlating increased incidence of the disease with higher elevations (Price 1976; Price and Bailey 1984; Molla et al. 2014; Deribe et al. 2015). In this paper, we focus on the parent material from which soils are derived. It has been noted by geologists that the orogenesis of the East African Rift contains individual igneous provinces that contain petrological and geochemical signatures from a variety of magma types including tholeiitic, transitional, alkaline, and ultraalkaline (Kampunzu and Mohr 1991; Kampunzu and Popoff 1991). Heterogeneity in soil type from Ethiopian soil maps suggests that the soils are locally derived (Schlüter 2006). The data from Le Blond et al. (2017), in particular, provide an excellent point of comparison between the bedrock data and soil data. By using these two in conjunction, we can begin to piece together a story for what geological pathway might lead to a soil composition which plays a role in the onset of podoconiosis. To investigate bedrock chemical compositional factors related to podoconiosis, we compiled a large data set from five regions known to have (currently or historically) published cases of podoconiosis: Cameroon Line, Cape Verde Islands, Mid-African Rift System, East African Rift System, and the Red Sea Rift. Geological histories suggest an influence from hot spot activity for all regions, and from rifting for all except the Cape Verde Islands (Fitton 1987; Déruelle et al. 1991; Kampunzu and Mohr 1991; Kampunzu and Popoff 1991; Anderson and Schramm 2005; Ramalho 2011). The Hawaiian Islands were used as an out-group due to the lack of podoconiosis despite similarity to the African regions both in their geological origin (as volcanic centers associated with rifting and plume mechanics) and the manual agricultural techniques historically used there (Kirch 1997; Kirch and Zimmerer 2011). The goal of this study is to see whether a statistical comparison of the geochemistry from a large data set among these regions would identify a specific composition or element that suggests petrological processes unique to regions associated with podoconiosis.

\section{General methods}

Data source, screening, and transformation

Weight percentage data for 13 oxides $\left(\mathrm{SiO}_{2}, \mathrm{Al}_{2} \mathrm{O}_{3}\right.$, $\mathrm{MgO}, \mathrm{Fe}_{2} \mathrm{O}_{3}, \mathrm{TiO}_{2}, \mathrm{MnO}, \mathrm{CaO}, \mathrm{Na}_{2} \mathrm{O}, \mathrm{K}_{2} \mathrm{O}, \mathrm{P}_{2} \mathrm{O}_{5}$, $\mathrm{B}_{2} \mathrm{O}_{3}, \mathrm{Cr}_{2} \mathrm{O}_{3}$, and $\mathrm{NiO}$ ) were downloaded September 2012 from the Geochemistry of Rocks of the Oceans and Continents (GEOROC) Web site (http://georoc. mpch-mainz.gwdg.de/georoc/) for five regions hosting published cases of podoconiosis (Cameroon Line, Cape Verde Islands, Mid-African Rift System, East African Rift System, Red Sea Rift) and one control region (Hawaiian Islands) giving a starting sample size of $n=14,527$ cases. For each case, weight percentages for the oxides were summed and, following Kovacs et al. (2001), those cases whose total percentage fell between 98 and 102\% $(n=12,013)$ were retained for further analysis. Due to low sample numbers, the oxides $\mathrm{B}_{2} \mathrm{O}_{3}, \mathrm{Cr}_{2} \mathrm{O}_{3}$, and $\mathrm{NiO}$ were omitted from analyses.

Zeroes in the original data were treated as rounded zeros (below detection values) and replaced using additive zero replacement (Aitchison 1986). All weight percentages were centered log-ratio (clr) transformed prior to statistical analysis (Grunsky 2010; Pawlowsky-Glahn and Egozcue 2012), where 
clr $=\ln$ (oxide weight $\%$ /geometric mean of composition). Using data from the remaining ten oxides, we identified multivariate outliers $(n=573)$ using Mahalanobis distance (Mertler and Vannatta 2005) and excluded these from analyses. Some cases $(n=887)$ were missing values for one or more of the ten oxides. For descriptive statistics, and AFM (Alkali $[\mathrm{Na}+\mathrm{K}]$, $\mathrm{Fe}, \mathrm{Mg}$ ) and TAS (total alkali-silica) plots, pairwise deletion was employed resulting in a total $n=11,440$, and minimum and maximum pairwise sample sizes for oxide by region of $n=36$ (MnO, Cameroon Line) and $n=8319\left(\mathrm{SiO}_{2}\right.$ and others, Hawaiian Islands), respectively (see Online Resource 1). A map of these locations is provided as Online Resource 2. Listwise deletion was employed for all other analyses giving a total (all regions included) $n=10,553$. Insufficient cases remained from the Cameroon Line when listwise deletion was employed; therefore, data from this region were only included in descriptive statistics, and AFM and TAS plots. Thus, the final data set for PCA, DFA, and analysis of variance (ANOVA) (derived by listwise deletion) included five regions (Cape Verde Islands [ $n=718]$, Mid-African Rift [ $n=328]$, East African Rift System $[n=1926]$, Red Sea Rift [ $n=79]$, Hawaiian Islands $[n=7502])$ and ten oxides $\left(\mathrm{SiO}_{2}, \mathrm{Al}_{2} \mathrm{O}_{3}, \mathrm{MgO}, \mathrm{Fe}_{2} \mathrm{O}_{3}, \mathrm{TiO}_{2}, \mathrm{MnO}, \mathrm{CaO}, \mathrm{Na}_{2} \mathrm{O}\right.$, $\mathrm{K}_{2} \mathrm{O}$, and $\mathrm{P}_{2} \mathrm{O}_{5}$ ).

\section{Statistical analyses}

All statistical tests were conducted using SPSS 23.0 for Windows (Statistical Package for the Social Sciences, Inc., Chicago, Illinois, USA) with $\alpha=0.05$. Following Nakagawa (2004), we chose not to adjust $\alpha$ for multiple tests. Despite centered logratio transformation, data did not strictly meet parametric assumptions. Unless indicated otherwise, measures of central tendency presented are mean \pm 1 S.E. Individual models are specified in Results section. We further computed effect sizes, which are independent of sample size (in contrast to statistical significance) and more readily compared among different data sets and different studies (Hojat and Xu 2004; Nakagawa and Cuthill 2007). For pairwise comparisons, we relied on Cohen's $d$ using pooled standard deviation (Hojat and $\mathrm{Xu}$ 2004), for which values of $\sim 0.2, \sim 0.5, \geq 0.8$ are generally considered small, moderate, and large, respectively (Cohen 1988). For DFA and ANOVA, we computed multivariate eta- squared $\left(\eta^{2}\right)$ and $\eta^{2}$, respectively, with values of $\sim$ $0.01, \sim 0.06$, and $\geq 0.14$ loosely regarded as small, moderate, and large, respectively (Cohen 1988). Cohen's d provides a standardized unit of difference, whereas $\eta^{2}$ indicates the approximate proportion of variance explained.

\section{Results}

Descriptive statistics, and AFM, and TAS

The mean and standard deviation of untransformed weight percentages of $\mathrm{SiO}_{2}, \mathrm{Al}_{2} \mathrm{O}_{3}, \mathrm{MgO}, \mathrm{Fe}_{2} \mathrm{O}_{3 \text { total }}$, $\mathrm{TiO}_{2}, \mathrm{MnO}, \mathrm{CaO}, \mathrm{Na}_{2} \mathrm{O}, \mathrm{K}_{2} \mathrm{O}$, and $\mathrm{P}_{2} \mathrm{O}_{5}$ by region are reported in Fig. 1 (a table with these values and additional descriptive statistics can be found in Online Resource 2). Mean oxide percentages vary considerably for a given region, and there is substantial variation across regions for a given oxide. $\mathrm{SiO}_{2}$ shows the largest region means of any oxide, ranging between 44 and $54 \%$. $\mathrm{Al}_{2} \mathrm{O}_{3}$ has the next highest means with values of $13-17 \%$. $\mathrm{Fe}_{2} \mathrm{O}_{3 \text { total }}, \mathrm{CaO}$, and $\mathrm{MgO}$ have similar region means ranging between 5 and $11 \%$, and the remaining oxides have region means of less than $3 \%$. The coefficient of variation $(\mathrm{CoV}$; see Online Resource 2, data table) ranges quite dramatically among regions for most of the oxides.

Plotting an AFM diagram (Fig. 2a) using untransformed data for the six regions demonstrates both a

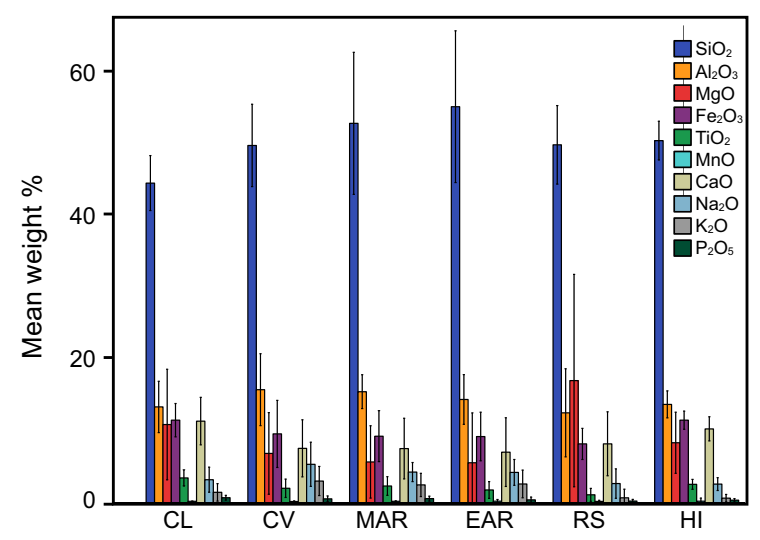

Fig. 1 Mean \pm 1 SD weight percentage (untransformed) of 10 oxides for the six regions $(\mathrm{CL}=$ Cameroon Line, $\mathrm{CV}=$ Cape Verde Islands, MAR = Mid-African Rift, EAR = East African Rift, RS = Red Sea Rift, HI = Hawaiian Islands) analyzed (total $n=11,440$; min. and max. pairwise sample sizes for oxide by region of $n=36$ and $n=8319$, respectively) 

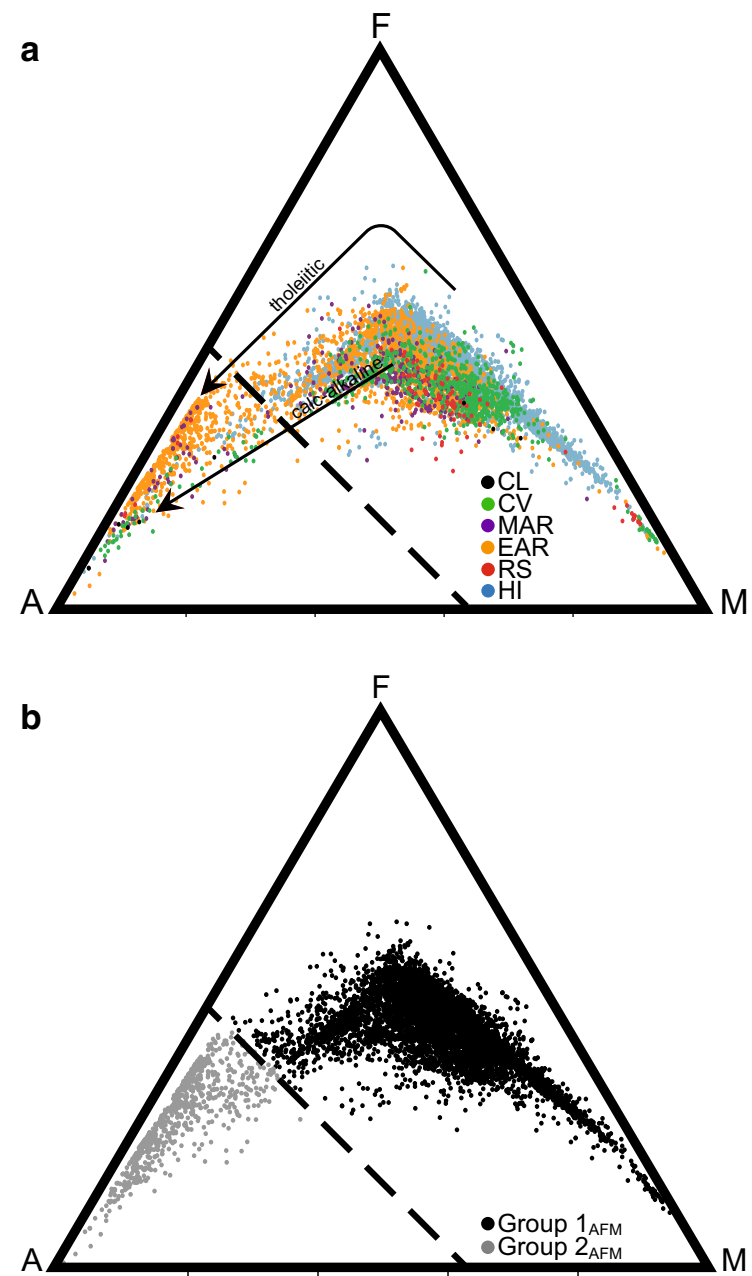

Fig. 2 AFM (Alkali $[\mathrm{Na}+\mathrm{K}], \mathrm{Fe}, \mathrm{Mg}$ ) diagram of untransformed data $(n=11,440)$ color coded to show a six regions $(\mathrm{CL}=$ Cameroon Line, $\mathrm{CV}=$ Cape Verde Islands, $\mathrm{MAR}=$ Mid-African Rift, EAR = East African Rift, RS = Red Sea Rift, $\mathrm{HI}=$ Hawaiian Islands) and $\mathbf{b}$ Group $1_{\mathrm{AFM}}$ and Group $22_{\mathrm{AFM}}$ created by clustering of data and defined by visual inspection according to the line $\mathrm{y}=(-75 / 63)\left(\mathrm{MgO} \%+\mathrm{Fe}_{2} \mathrm{O}_{3}\right.$ total $\left.) / 2\right)+75$

tholeiitic differentiation trend and a calc-alkaline differentiation trend. For each of the African regions, data points on the AFM diagram separate into two visually distinct clusters, a phenomenon not observed for Hawaiian data points. Using visual inspection, we created a line, defined by the equation $y=\left(-\frac{75}{63}\right)\left(\left(\mathrm{MgO} \%+\frac{\mathrm{Fe}_{2} \mathrm{O}_{3}}{2}\right)+75\right)$, that separates the two clusters. It is of note that cases from all regions studied can be found in both groups. However, the majority of all cases, and almost all the Hawaiian
Island cases, fall into one cluster, while the second cluster is comprised of a majority of East African Rift cases. The first group (located to the right of the dashed line on the AFM diagram) is high in $\mathrm{MgO}$, intermediate to high in $\mathrm{Fe}_{2} \mathrm{O}_{3 \text { total }}$, and very low in $\mathrm{Na}_{2} \mathrm{O}$ and $\mathrm{K}_{2} \mathrm{O}$. The second group (located to the left of the dashed line on the AFM diagram) is very low in both $\mathrm{MgO}$ and $\mathrm{Fe}_{2} \mathrm{O}_{3 \text { total }}$ and very high in $\mathrm{Na}_{2} \mathrm{O}$ and
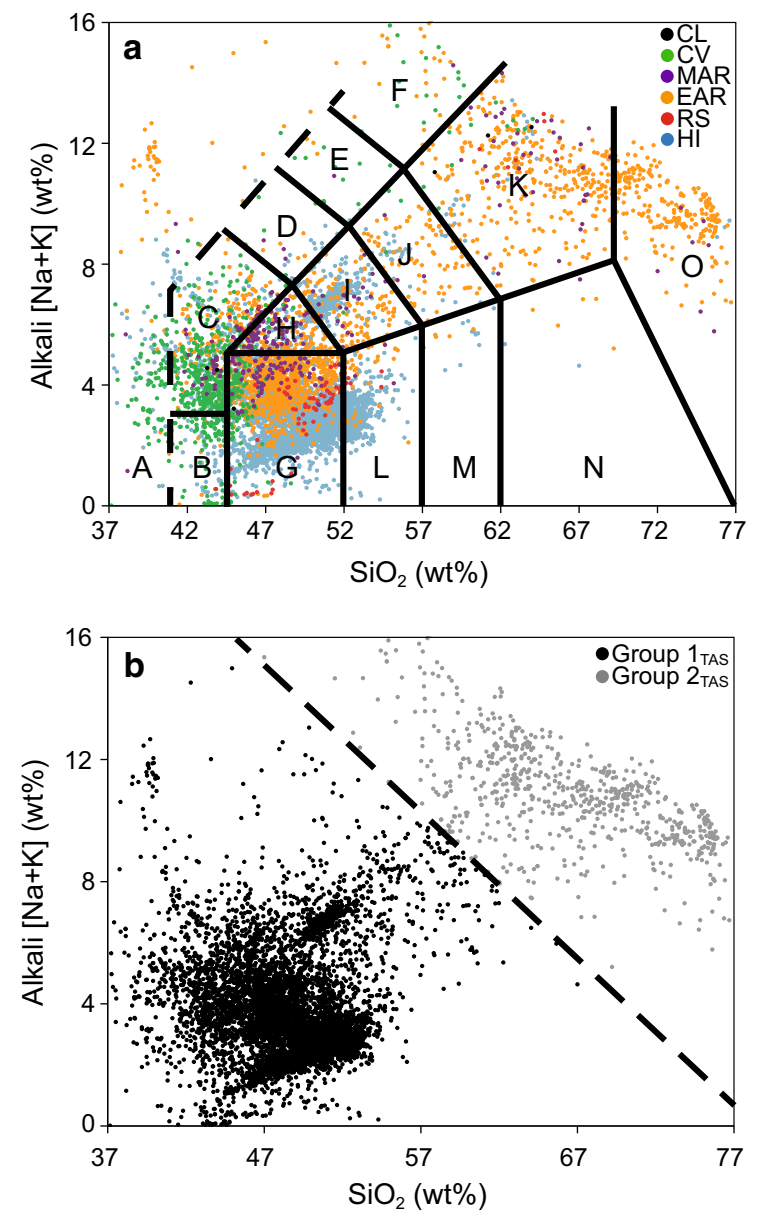

Fig. 3 TAS (total alkali silica) diagram of untransformed data $(n=11,440)$ color coded to show a six regions $(\mathrm{CL}=$ Cameroon Line, $\quad \mathrm{CV}=$ Cape Verde Islands, $\mathrm{MAR}=$ Mid-African Rift, EAR = East African Rift, RS = Red Sea Rift, HI = Hawaiian Islands). Names of equivalent rock types: (A)-Foldite, (B)-Picrobasalt, (C)-Tephrite/Basanite, (D)-Phonotephrite, (E)-Tephri-phonolite, (F)-Phonolite, (G)-Basalt, (H)-Trachybasalt, (I)-Basaltic trachyandesite, (J)-Trachy-andesite, (K)-Trachyte/Trachydacite, (L)-Basaltic andesite, (M)Andesite, (N)-Dacite, (O)-Rhyolite (Le Maitre et al. 2002). b The same diagram color coded to show Group $1_{\text {TAS }}$ and Group 2 TAS created by clustering of data and defined by visual inspection according to the line $\mathrm{y}=\left((-19.5 / 42)\left(\mathrm{SiO}_{2} \mathrm{wt} \%\right)\right)+$ 36.7 
$\mathrm{K}_{2} \mathrm{O}$. We coded the separated data points into a dichotomous grouping variable (Groups $1_{\mathrm{AFM}}$ and 2 AFM, Fig. 2b). A TAS diagram shows a similar clustering of data points into two groups (Fig. 3a) that we separated along the line, $y=\left(-\frac{19.5}{42}\right)\left(\mathrm{SiO}_{2} \%\right)+36.7$, as indicated (dashed line) in Fig. 3b. As before, we coded the separated data points into a dichotomous grouping variable (Groups $1_{\text {TAS }}$ and 2 TAS, Fig. 3b). Note that Group 2 TAS, like Group 2 AFM, falls into the high alkaline category comprised of phonolite, trachyte, dacite, and rhyolite. Group $1_{\mathrm{TAS}}$ is highly basaltic in its origin.

Analysis of oxides by region

\section{Principal component analysis}

We employed PCA to investigate what latent structure is present in the set of clr-transformed weight percentages of ten oxides $\left(\mathrm{SiO}_{2}, \mathrm{Al}_{2} \mathrm{O}_{3}, \mathrm{MgO}, \mathrm{Fe}_{2} \mathrm{O}_{3}\right.$ total, $\mathrm{TiO}_{2}, \mathrm{MnO}, \mathrm{CaO}, \mathrm{Na}_{2} \mathrm{O}, \mathrm{K}_{2} \mathrm{O}$, and $\mathrm{P}_{2} \mathrm{O}_{5}$; total $n=10,553$ ) that might relate to regions known to have podoconiosis. Principal component analysis was conducted using a varimax rotation. Eigenvalue and variance criteria (Mertler and Vannatta 2005) indicate a two-component solution, with components 1 and 2 accounting for 51.1 and $25.9 \%$ of the total variance in the original variables, respectively. Figure 4 presents the loadings for each component. The highest loading oxides on component 1 are $\mathrm{K}_{2} \mathrm{O}, \mathrm{MgO}$, and $\mathrm{CaO}$ with $92.5,90.8$, and $89.9 \%$ of their variability, respectively, explained by the two-component solution. Oxides with highest loadings on component 2 are $\mathrm{SiO}_{2}$ and $\mathrm{P}_{2} \mathrm{O}_{5}$ with 91.5 and $68.7 \%$ of their variability, respectively, explained by the model.

When cases are plotted based on component scores (Fig. 5a), two clusters of data points become visible (reminiscent of those seen in the AFM diagram (Fig. 2a) and the TAS diagram (Fig. 3a)). Those two clusters, named Group $1_{\mathrm{PCA}}$ and Group $2_{\mathrm{PCA}}$, were separated based on visual inspection, along the line defined by the equation $y=\left(-\frac{5.5}{2}\right)$ (component 1$)$, (Fig. 5b). An independent samples $t$ test determines that scores on principal component 1 are larger for Group $1_{\mathrm{PCA}}(0.19 \pm 0.01)$ than for Group $2_{\mathrm{PCA}}$ $(-2.69 \pm 0.02 ; \quad t(853.66)=124.01, \quad p<0.001$, Cohen's $d=4.14)$. In contrast, scores on principal component 2 are larger for Group $2_{\mathrm{PCA}}(1.98 \pm 0.06)$

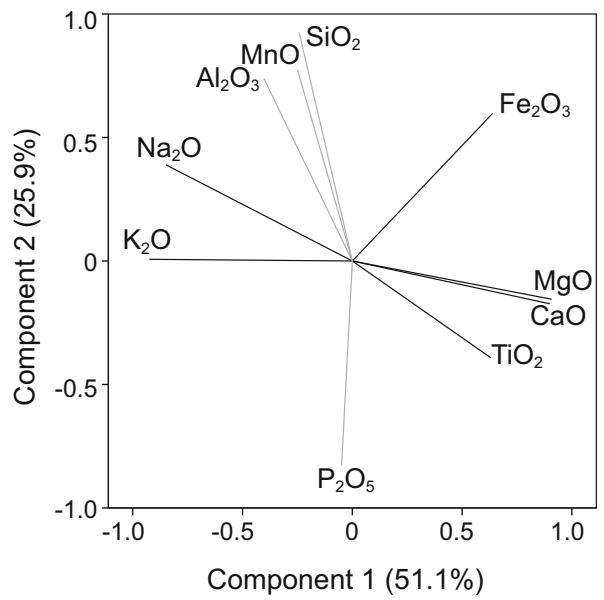

Fig. 4 Factor loadings for varimax rotated components from principal component analysis of 10 oxide variables (centered log-ratio transformed, $n=10,553$ )

than for Group $1_{\mathrm{PCA}} \quad(-0.14 \pm 0.01$; $t(727.14)=-35.38, p<0.001$, Cohen's $d=2.5)$. Examination of component scores (Fig. 5b) shows that component 1 provides the largest separation between Group $1_{\mathrm{PCA}}$ (characterized by larger relative amounts of $\mathrm{MgO}$ and $\mathrm{CaO}$ ) and Group $2 \mathrm{PCA}_{\mathrm{PA}}$ (characterized by larger relative amounts of $\mathrm{K}_{2} \mathrm{O}$ and $\mathrm{Na}_{2} \mathrm{O}$ ). By comparison, component 2 provides only minor separation between groups (with Group $1_{\mathrm{PCA}}$ characterized by smaller relative amounts of $\mathrm{SiO}_{2}$ and $\mathrm{Al}_{2} \mathrm{O}_{3}$ ). Effect sizes reveal that component 1 contributes more to the separation of Group $1_{\mathrm{PCA}}$ and Group 2 PCA than does component 2.

The efficacy of visual separation of Hawaiian and East African Rift cases using the line in Fig. 5b was confirmed by comparing the proportions of Groups $1_{\mathrm{PCA}}$ and 2 PCA comprised of Hawaiian and East African Rift cases (Table 1); while $76 \%$ of Group $1_{\text {PCA }}$ cases are from the Hawaiian Islands, only $7 \%$ of Group 2 cases are Hawaiian. In contrast, $80 \%$ of Group 2 PCA cases are from the East African Rift. Comparing the mean weight percentages of each oxide for Groups $1_{\mathrm{PCA}}$ and $2_{\mathrm{PCA}}$ (Table 2 ) reveals relatively large differences between the groups, as measured by Cohen's $d$, for almost every oxide. Ranking oxides by absolute value of Cohen's $d$ shows, not unexpectedly, a pattern similar to that seen when ranking oxides by magnitude of loadings from PCA, with larger standardized differences between Group $1_{\mathrm{PCA}}$ and $22_{\mathrm{PCA}}$ means observed for $\mathrm{Na}_{2} \mathrm{O}, \mathrm{CaO}, \mathrm{MgO}, \mathrm{K}_{2} \mathrm{O}$, and $\mathrm{TiO}_{2}$, 

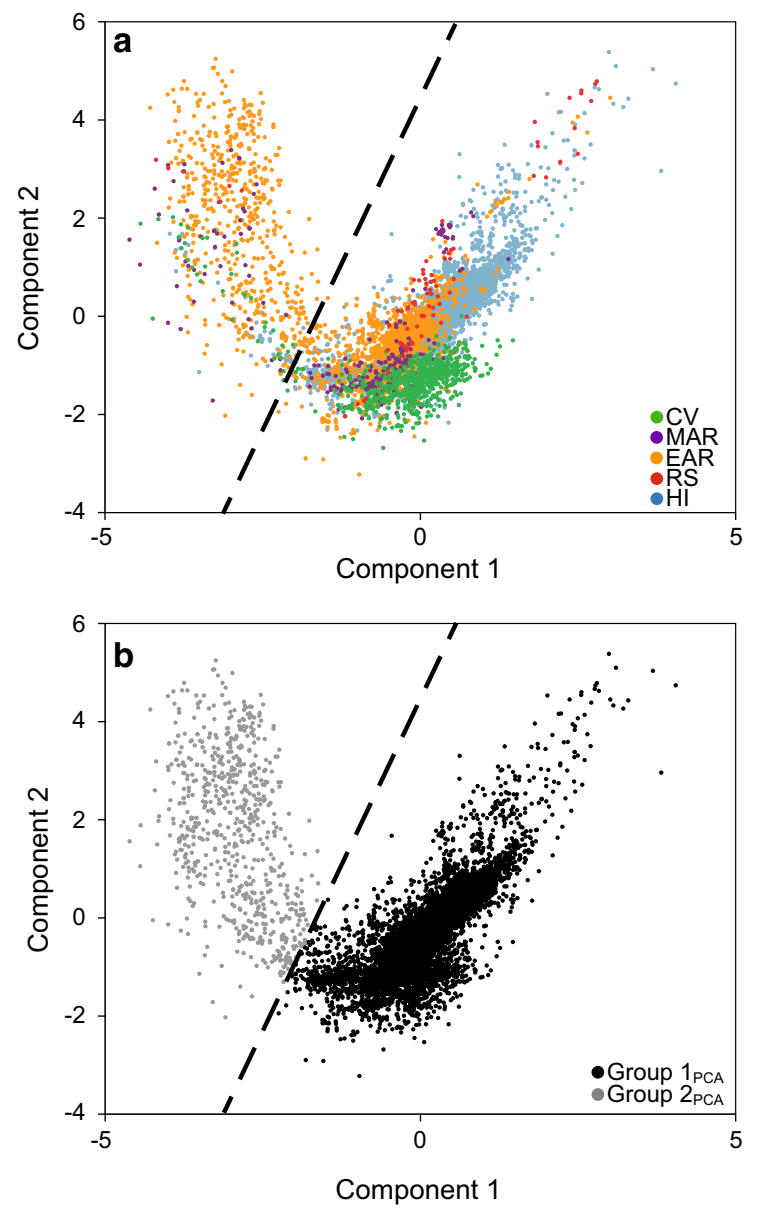

Fig. 5 Principal component scores on components 1 and 2 (centered log-ratio transformed data $[n=10,553]$ ) color coded to show a five regions and $\mathbf{b}$ Group $1_{\mathrm{PCA}}$ and Group $2_{\mathrm{PCA}}$ created by clustering of data and defined by visual inspection according to the line $\mathrm{y}=((-5.5 / 2)(\mathrm{Comp} 1))+45$. Note that group separation is greatest along component 1 (associated with incompatible $\mathrm{K}$ and $\mathrm{Na}$ and compatible $\mathrm{Mg}, \mathrm{Ca}$ ) and minimal along component 2 (associated with $\mathrm{Si}$ )

the oxides loading predominantly on component 1 . Smaller effect sizes are observed for $\mathrm{SiO}_{2}, \mathrm{Al}_{2} \mathrm{O}_{3}$, $\mathrm{MnO}$, and $\mathrm{P}_{2} \mathrm{O}_{5}$, the oxides loading predominantly on component 2. Cases comprising Group $1_{\mathrm{PCA}}$ and Group 2 2 PCA were mapped to look for geographic patterns in the data (Fig. 6), but no obvious patterns are visible.

Close correspondence of the cases between AFM, TAS, and PCA groups was suspected due to the variables in common among the three approaches (i.e., oxides utilized in AFM and TAS plots are subsets of those used for PCA, and AFM and TAS have alkali oxides in common). Indeed, close correspondence is confirmed upon examination of the overlap in case classification (Fig. 7); 10,375 (98.3\%) of the 10,553 cases were classified similarly by the three approaches. The similarity among corresponding groups is visually apparent upon comparing AFM, TAS, and PCA diagrams with groups defined by means of alternative plotting methods (Fig. 8).

\section{Discriminant function analysis}

A direct discriminant function analysis was performed using the clr-transformed weight percentages of ten oxides $\left(\mathrm{SiO}_{2}, \mathrm{Al}_{2} \mathrm{O}_{3}, \mathrm{MgO}, \mathrm{Fe}_{2} \mathrm{O}_{3 \text { total }}, \mathrm{TiO}_{2}, \mathrm{MnO}\right.$, $\mathrm{CaO}, \mathrm{Na}_{2} \mathrm{O}, \mathrm{K}_{2} \mathrm{O}$, and $\mathrm{P}_{2} \mathrm{O}_{5}$ ) as predictors of a case's geographic region of origin (Cape Verde Islands, MidAfrican Rift, East African Rift, Red Sea Rift, and Hawaiian Islands; $n=10,553$ ). Prior probabilities were computed from group sizes (Mertler and Vannatta 2005), and cases were classified based on leaveone-out classification, a jackknifing procedure that classifies each case by the functions derived from all cases other than the omitted case.

Four discriminant functions were calculated with a combined $\Lambda=0.41, \chi^{2}(40, n=10,553)=9450.38$, $p<0.001$, multivariate $\eta^{2}=0.20$, indicating that region accounts for $20 \%$ of model variance. Table 3 presents structure matrix correlations and standardized function coefficients. All of the predictors have their highest proportion of variance extracted by either functions 1 or 2 (Table 3 structure matrix). Function 1 has $46 \%$ of its variance explained by region and accounts for $73 \%$ of the model's between-groups variance. Examination of structure matrix correlations reveals that $\mathrm{K}_{2} \mathrm{O}$ is the most important predictor of region without controlling for the remaining predictors, with function 1 extracting $73 \%$ of the variance from $\mathrm{K}_{2} \mathrm{O}$. Examination of standardized function coefficients indicates that the most important predictors in function 1 after controlling for the remaining predictors (i.e., the predictors making the largest unique contributions) are $\mathrm{K}_{2} \mathrm{O}(1.08)$ and $\mathrm{SiO}_{2}$ $(-0.78)$.

Function $2 \quad\left(\Lambda=0.75, \quad \chi^{2}(27, \quad n=10,553)=\right.$ $3021.48, p<0.001, \eta^{2}=0.19$ ) has $19 \%$ of its variance explained by region and accounts for $21 \%$ of the model's between-groups variance. Structure matrix correlations reveal the most important predictor is $\mathrm{SiO}_{2}$, with function 2 extracting $52 \%$ of the variance 
Table 1 Number of cases from each region comprising PCA Groups 1 and 2, and the percentage of PCA Groups 1 and 2 cases by region $(\mathrm{CV}=$ Cape Verde Islands, MAR $=$ Mid-African Rift, EAR = East African Rift, RS = Red Sea Rift, HI = Hawaiian Islands $)$

\begin{tabular}{|c|c|c|c|c|}
\hline Location & PCA Group $1 n$ & $\%$ of PCA Group 1 cases & PCA Group $2 n$ & $\%$ of PCA Group 2 cases \\
\hline $\mathrm{CV}$ & 683 & 7 & 35 & 5 \\
\hline MAR & 279 & 3 & 49 & 7 \\
\hline EAR & 1364 & 14 & 562 & 80 \\
\hline RS & 73 & $<1$ & 6 & $<1$ \\
\hline HI & 7450 & 76 & 52 & 7 \\
\hline Total & 9849 & 100 & 704 & 100 \\
\hline
\end{tabular}

Note that $76 \%$ of Group 1 cases are from the Hawaiian Islands while $80 \%$ of Group 2 cases are from the East Africa Rift

from $\mathrm{SiO}_{2}$. The predictors making the largest unique contributions to function 2 are $\mathrm{TiO}_{2}(0.85)$ and $\mathrm{Fe}_{2} \mathrm{O}_{3 \text { total }}(-0.81)$. Function $3\left(\Lambda=0.93, \chi^{2}(16\right.$, $\left.n=10,553)=787.33, p<0.001, \eta^{2}=0.04\right)$ has $4 \%$ of its variance explained by region and accounts for $4 \%$ of the model's between-groups variance. Large unique contributions to function 3 come from $\mathrm{MgO}$ (1.44), $\mathrm{Na}_{2} \mathrm{O}(0.95)$ and $\mathrm{P}_{2} \mathrm{O}_{5}$ (0.56). Function 4 $\left(\Lambda=0.97, \chi^{2}(7, n=10,553)=340.66, p<0.001\right.$, $\left.\eta^{2}=0.03\right)$ has $3 \%$ of its variance explained by region and accounts for $3 \%$ of the model's between-groups

Table 2 Mean \pm 1 SD weight percentage (untransformed) of ten oxides for PCA Groups $1(n=9849)$ and $2(n=704)$. Cohen's $d$ for the difference in means (calculated using centered log-ratio transformed data) between Group 1 and Group 2 for each oxide is also provided

\begin{tabular}{lrrrrrr}
\hline Oxide & \multicolumn{2}{c}{ PCA Group 1 } & & \multicolumn{2}{c}{ PCA Group 2 } & Cohen's $d$ \\
\cline { 2 - 3 } & Mean & SD & & Mean & SD & \\
\hline $\mathrm{Na}_{2} \mathrm{O}$ & 2.74 & 0.98 & & 6.00 & 1.40 & -5.53 \\
$\mathrm{CaO}$ & 10.32 & 1.80 & & 2.22 & 2.54 & 5.31 \\
$\mathrm{MgO}$ & 8.29 & 4.38 & & 1.08 & 2.73 & 4.75 \\
$\mathrm{~K}_{2} \mathrm{O}$ & 0.81 & 0.77 & & 4.30 & 1.23 & -4.22 \\
$\mathrm{TiO}_{2}$ & 2.62 & 0.75 & & 0.80 & 0.71 & 3.84 \\
$\mathrm{SiO}_{2}$ & 49.36 & 3.19 & & 64.33 & 7.36 & -3.19 \\
$\mathrm{Al}_{2} \mathrm{O}_{3}$ & 13.85 & 2.11 & & 14.78 & 3.09 & -3.05 \\
$\mathrm{MnO}$ & 0.18 & 0.04 & & 0.22 & 0.09 & -2.75 \\
$\mathrm{P}_{2} \mathrm{O}_{5}$ & 0.40 & 0.28 & & 0.20 & 0.25 & 1.58 \\
$\mathrm{Fe}_{2} \mathrm{O}_{3}$ & 11.42 & 1.34 & & 6.07 & 2.27 & 1.02 \\
\hline
\end{tabular}

Note the higher mean values of $\mathrm{K}_{2} \mathrm{O}, \mathrm{Na}_{2} \mathrm{O}$, and $\mathrm{SiO}_{2}$ for PCA Group 2 variance, with large unique contributions from $\mathrm{Al}_{2} \mathrm{O}_{3}$ (0.75) and $\mathrm{CaO}(-0.79)$.

Classification results (Table 4) reveal that $78.4 \%$ of all cases are identified correctly (compared to an expected hit ratio by chance of $54.4 \%$ ). Crossvalidation results (data not shown) are virtually identical, with $78.4 \%$ cases identified correctly. In order to assess the accuracy of prediction of group membership while taking into account chance agreement, we computed a kappa coefficient (Green and Salkind 2005) and obtained a value of 0.48 indicating moderate accuracy in prediction. Hawaiian Islands and the East African Rift have the highest levels of correct classification ( 92.4 and $53.5 \%$, respectively). Cape Verde Islands, the Mid-African Rift, and Red Sea Rift are more frequently misclassified as the Hawaiian Islands (57.4, 51.2, and 46.8\%, respectively) than correctly classified. The Mid-African Rift is also frequently misclassified as East African Rift (24.4\%).

The mean discriminant score for each region by discriminant function is presented in Table 5, and a plot depicting individual cases and region group centroids in discriminant function space defined by the first two discriminant functions is shown in Fig. 9a. The same discriminant function scores plot as in Fig. 9a was coded by group classification defined by PCA to produce Fig. 9b. An independent samples $t$ test determines that scores on discrimination function 1 are larger for Group $2_{\mathrm{PCA}}(3.13 \pm 0.03)$ than for Group $1_{\text {PCA }}(-0.22 \pm 0.01 ; t(871.17)=-98.58$, $p<0.001$, Cohen's $d=-3.15$ ). In contrast, scores on discriminant function 2 are larger for Group $1_{\mathrm{PCA}}$ $(0.11 \pm 0.01)$ than for Group $2_{\mathrm{PCA}}(-1.56 \pm 0.07$; $t(734.34)=25.32, p<0.001$, Cohen's $d=1.62)$. 


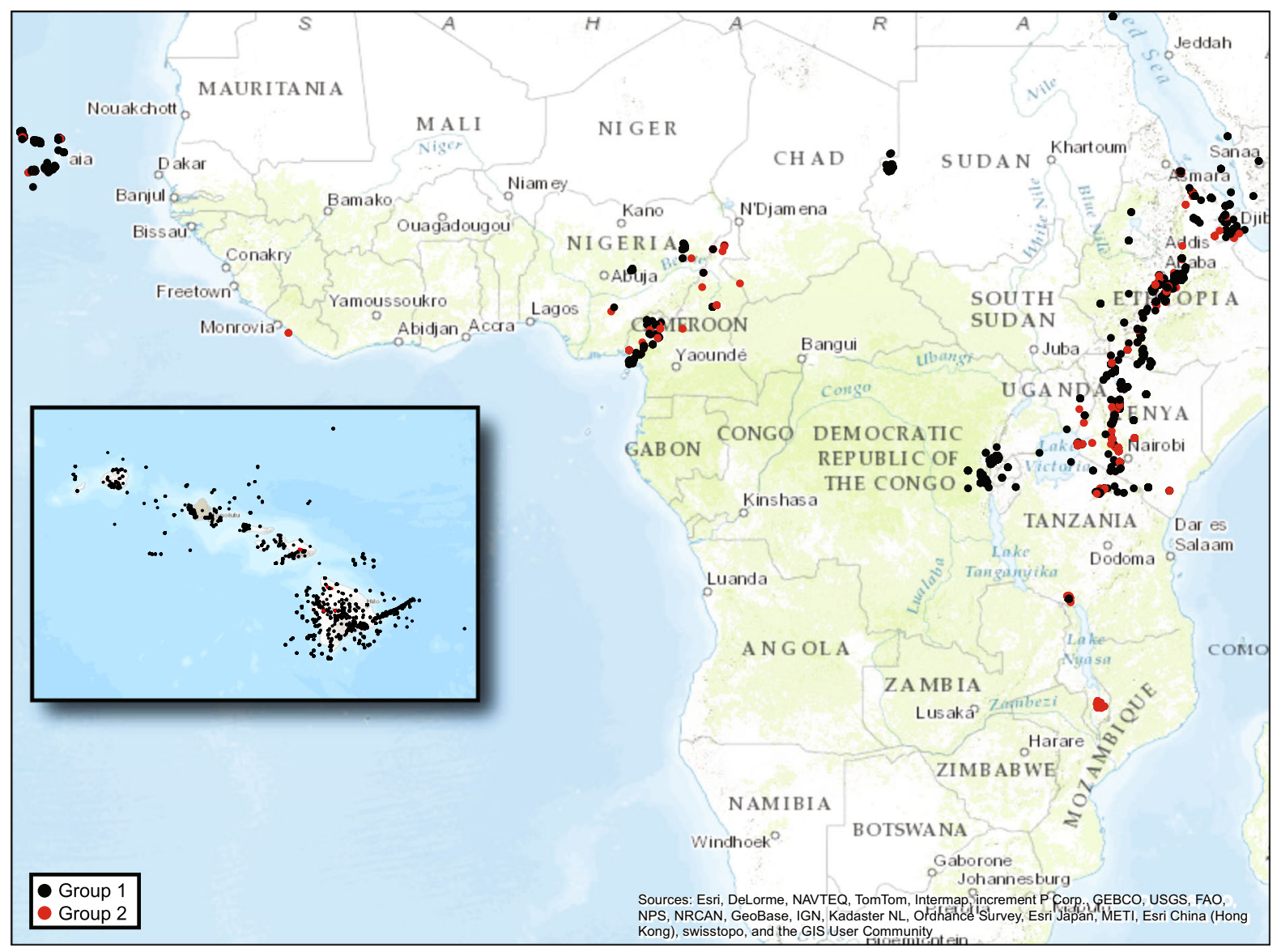

Fig. 6 Locations of individual cases $(n=10,553)$ used in this study color coded into Group $1_{\text {PCA }}(n=9849)$ and Group 2 PCA $(n=704)$. Considerable overplotting occurs at this scale

Data from PCA-coded groups (Fig. 9b), in conjunction with structure matrix correlations (Table 3), reveal that function 1 discriminates well between Group $1_{\mathrm{PCA}}$ (characterized by smaller relative amounts of $\mathrm{K}_{2} \mathrm{O}$ ) and Group $2_{\mathrm{PCA}}$ (characterized by larger relative amounts of $\mathrm{K}_{2} \mathrm{O}$ ). Conceptualized in terms of locations (Fig. 9a), function 1 shows the largest separation between the Hawaiian Islands and the East African Rift (confirmed by calculating the difference in mean discriminant scores on DF1 from Table 5), though there is considerable overlap between the African locations. In comparison with function 1, function 2 shows relatively minimal discrimination between Group $1_{\mathrm{PCA}}$ (characterized by smaller relative amounts of $\mathrm{SiO}_{2}$ and $\mathrm{Al}_{2} \mathrm{O}_{3}$ ) and Group $2_{\mathrm{PCA}}$ (characterized by larger relative amounts of $\mathrm{SiO}_{2}$ and $\mathrm{Al}_{2} \mathrm{O}_{3}$ ) and provides no discrimination between landmasses (i.e., African vs. Hawaiian cases).
Considering discriminant function scores on all four functions simultaneously, an examination of pairwise group comparisons (Table 6) indicates that every region's centroid is significantly distant from every other region's centroid $(p<0.001$ for all comparisons). The $F$ statistics from pairwise group comparisons (the magnitudes of which can be used to compare Mahalanobis distances between groups in multivariate space) reveal the largest separation exists between the Hawaiian Island and East African Rift centroids $(F=810.73)$, while the smallest separation is between East African Rift and Mid-African Rift $(F=67.10)$.

Analysis of silicon:aluminum ratio by region

Price and Henderson (1978) hypothesized that podoconiosis may be associated with the ratio of 


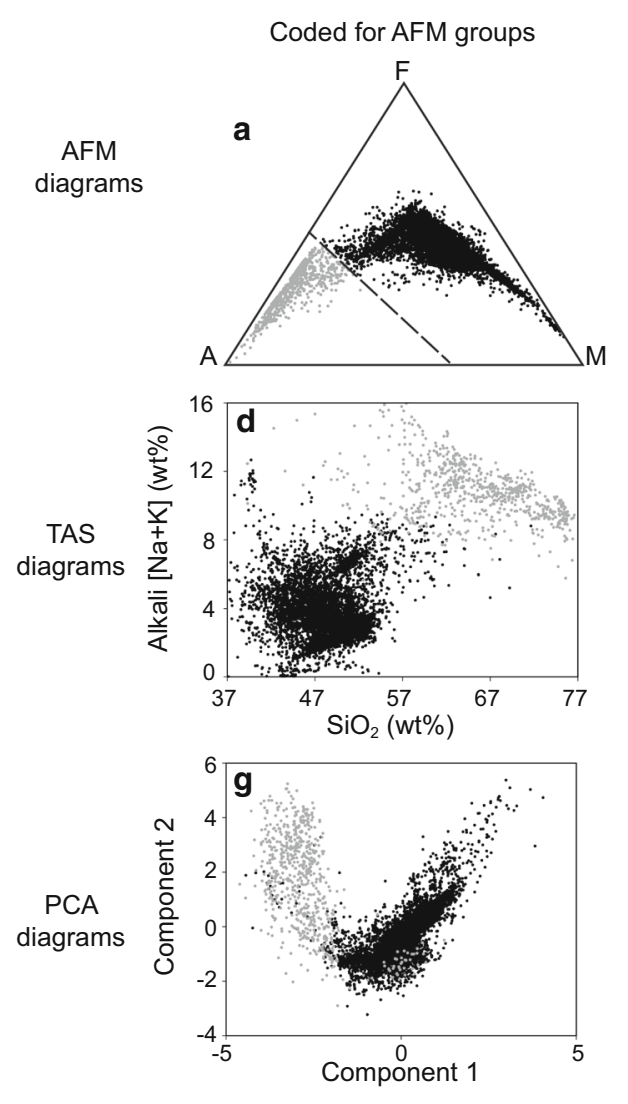

Fig. 7 AFM, TAS and PCA diagrams coded to visualize similarity in classification of cases into groups. a AFM original, b AFM with cases colored according to TAS groups, c AFM with cases colored according to PCA groups, $\mathbf{d}$ TAS with cases

silicon to aluminum in the soil. By testing for a difference in the $\mathrm{SiO}_{2}: \mathrm{Al}_{2} \mathrm{O}_{3}$ ratio among the five regions, including those associated with (Cape Verde Islands, Mid-African Rift, East African Rift, Red Sea Rift) and those not associated with (Hawaii) podoconiosis, we sought to explore this hypothesis. Thus, we conducted a one-way ANOVA treating the ratio of clrtransformed $\mathrm{SiO}_{2}$ to clr-transformed $\mathrm{Al}_{2} \mathrm{O}_{3}$ as the dependent variable and region as a between-subjects factor. Ratios less than 1 indicate that, on average, the deviation from the geometric mean of the composition for $\mathrm{Al}_{2} \mathrm{O}_{3}$ is greater than that of $\mathrm{SiO}_{2}$. Results indicate a significant difference in the $\mathrm{SiO}_{2}: \mathrm{Al}_{2} \mathrm{O}_{3}$ ratio among regions $\quad(F(4, \quad 10,548)=211.28, \quad p<0.001$, $\left.\eta^{2}=0.07\right)$, with $7 \%$ of the variance in the ratio explained by region. Tamhane post hoc tests reveal the ratio for the Cape Verde Islands $(0.50 \pm 0.002)$ is significantly lower than for all other regions (Cohen's
Coded for TAS groups
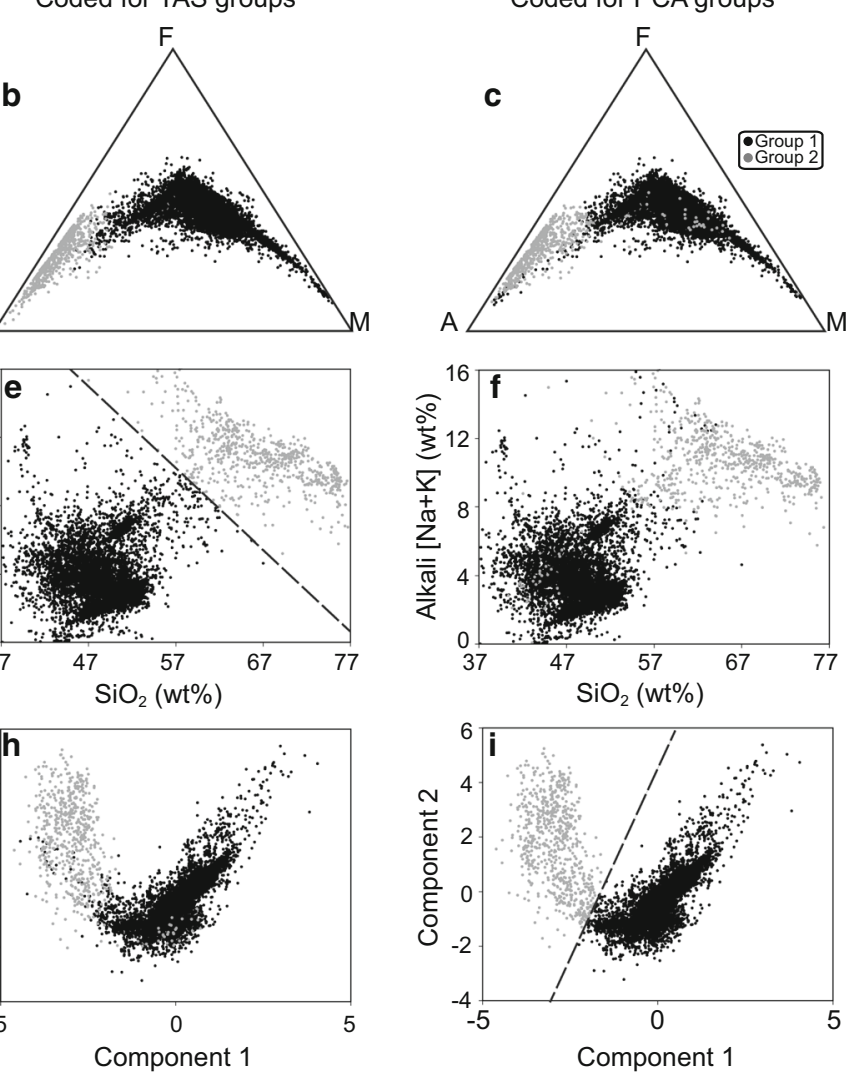

colored according to AFM groups, e TAS original, $\mathbf{f}$ TAS with cases colored according to PCA groups, g PCA with cases colored according to AFM groups, $\mathbf{h}$ PCA with cases colored according to TAS groups, $\mathbf{i}$ PCA original

$d 0.58-0.94)$. Furthermore, the ratio for the Hawaiian Islands $(0.53 \pm 0.001)$, while significantly greater than that of Cape Verde Islands (Cohen's $d$ 0.58), is significantly lower than for all remaining regions (Cohen's $d$ 0.55-0.98). The $\mathrm{SiO}_{2}: \mathrm{Al}_{2} \mathrm{O}_{3}$ ratio of the East African Rift $(0.55 \pm 0.001)$, Mid-African Rift $(0.56 \pm 0.003)$, and the Red Sea Rift $(0.57 \pm 0.005)$ is not significantly different from one another (Cohen's $d$ 0.10-0.26). A nonparametric Kruskal-Wallis ANOVA (results not shown) yields results identical to the parametric ANOVA. Untransformed $\mathrm{SiO}_{2}: \mathrm{Al}_{2} \mathrm{O}_{3}$ ratios can be found in Online Resource 3.

In addition to comparing $\mathrm{SiO}_{2}: \mathrm{Al}_{2} \mathrm{O}_{3}$ ratios among regions, we also wanted to determine whether there is a significant difference in this ratio between Group $1_{\text {PCA }}(n=9849)$ and Group $2_{\mathrm{PCA}}(n=704)$. A pattern in the Harker diagram (bivariate scatterplot of $\mathrm{SiO}_{2}$ vs. $\mathrm{Al}_{2} \mathrm{O}_{3}$; Fig. 10) shows Group 2 PCA further to the right 

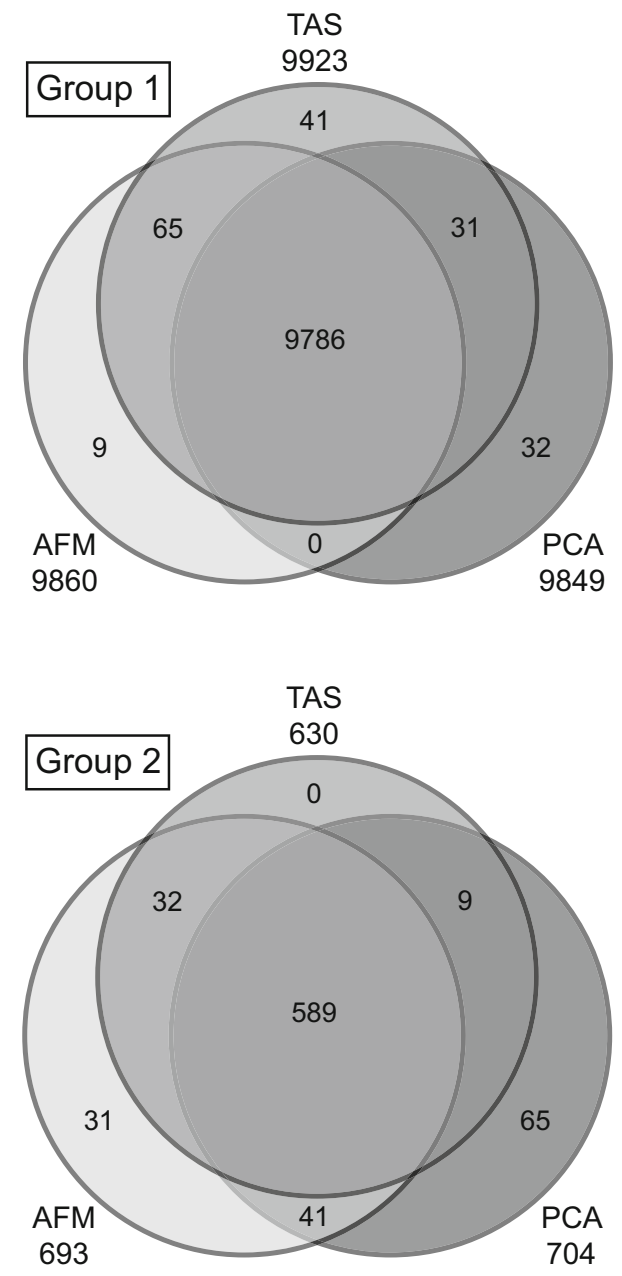

Fig. 8 Number of cases classified similarly into Group 1 and Group 2 using the approaches of AFM, TAS, and PCA. Venn diagrams only include the $n=10,553$ cases common to all three approaches. Areas of overlap are not to scale

(higher $\mathrm{SiO}_{2}$ ) for a given weight $\% \mathrm{Al}_{2} \mathrm{O}_{3}$ than Group $1_{\mathrm{PCA}}$ cases. An independent samples $t$ test reveals the untransformed ratio for Group $2_{\mathrm{PCA}}(0.58 \pm 0.002)$ is significantly larger than for Group $1_{\mathrm{PCA}}$ $(0.53 \pm 0.001 ; \quad t(785.23)=-26.09, \quad p<0.001$, Cohen's $d=1.12$ ).

\section{Discussion}

Podoconiosis is a complicated disease to study, not only because of the complexity of the human body, but also because of the disease's large and varied geographic range. The current model of podoconiosis posits fine-grained minerals entering the lymphatic system leading to an inflammatory response. However, within Ethiopia, for example, the presence of the disease in only certain towns suggests other causative factors could be a local soil composition or texture that should be related to the bedrock composition. Indeed, research into podoconiosis has consistently noted the local variability of the disease and its associated soils (Oomen 1969; Price 1974a, b; Price et al. 1981; Deribe et al. 2013, 2015). Previous investigation of podoconiosis correlated the disease with the "tropical red soil" and, by extension, its source rock (Price et al. 1981; Price and Bailey 1984). This current, exploratory study searches for specific bedrock elements or element suites associated with the disease with an aim to narrow future geological research efforts. Results of this study support previous hypotheses that a unique alkaline- and silica-rich geochemistry is associated with podoconiosis and provide suggestions for future research.

We propose there is a unique geochemistry associated with Group 2 that is of interest to podoconiosis research. The presence of a unique geochemical subset worthy of deeper analysis was first identified in the two-cluster separation of cases that is readily apparent by AFM (Fig. 2), TAS (Fig. 3), principal component scores diagram (Fig. 5), and discriminant function scores diagram (Fig. 9). Although the findings from these plots and analyses are not independent given that they share sets or subsets of variables, the fact that the same cases repeatedly show up in the same cluster (i.e., either Group 1 or Group 2) among analyses (see Fig. 7) lends support for the presence of a unique geochemistry of Group 2. The presence of East African Rift cases in both Group 1 and Group 2 is consistent with literature on podoconiosis which reports that the incidence of the disease in Ethiopia is locally variable. The lack of clearly defined geographic borders between Group $1_{\mathrm{PCA}}$ and Group $2_{\text {PCA }}$ (Fig. 6) mimics, in a general sense, the localscale variation in the presence/absence of podoconiosis. By coding our cases into Group 1 or Group 2 based on which side of the line of separation they fell (Figs. 2,3,5), we were able to identify which elements contribute most to the separation of these two groups. The highly alkaline nature of Group 2 geochemistry is supported by both principal component 1 and discriminant function 1 , which are most associated with $\mathrm{Mg}, \mathrm{Ca}, \mathrm{Na}$, and $\mathrm{K}$. In addition to confirming high 
Table 3 Structure matrix correlations and standardized function coefficients from discriminant function analysis performed using the weight percentages (centered log-ratio transformed) of ten oxides as predictors of region (Cape Verde Islands, Mid-
African Rift, East African Rift, Red Sea Rift, and Hawaiian Islands; $n=10,553)$. The largest structure matrix correlation for a given oxide is starred

\begin{tabular}{|c|c|c|c|c|c|c|c|c|}
\hline \multirow[t]{2}{*}{ Oxide } & \multicolumn{4}{|c|}{ Structure matrix correlations } & \multicolumn{4}{|c|}{ Standardized function coefficients } \\
\hline & 1 & 2 & 3 & 4 & 1 & 2 & 3 & 4 \\
\hline $\mathrm{K}_{2} \mathrm{O}$ & $0.85^{*}$ & 0.05 & -0.06 & 0.38 & 1.08 & 0.43 & 0.03 & 0.17 \\
\hline $\mathrm{CaO}$ & $-0.61^{*}$ & 0.16 & 0.25 & -0.31 & 0.28 & 0.04 & -0.09 & -0.79 \\
\hline $\mathrm{MgO}$ & $-0.58^{*}$ & 0.19 & 0.32 & -0.42 & -0.05 & 0.40 & 1.44 & -0.07 \\
\hline $\mathrm{Na}_{2} \mathrm{O}$ & $0.54^{*}$ & -0.38 & 0.12 & 0.37 & -0.17 & 0.03 & 0.95 & -0.44 \\
\hline $\mathrm{Fe}_{2} \mathrm{O}_{3}$ & $-0.46^{*}$ & -0.42 & -0.16 & 0.29 & 0.21 & -0.81 & -0.23 & 0.43 \\
\hline $\mathrm{SiO}_{2}$ & 0.04 & $-0.72^{*}$ & -0.04 & 0.32 & -0.78 & 0.35 & 0.13 & 0.17 \\
\hline $\mathrm{Al}_{2} \mathrm{O}_{3}$ & 0.17 & $-0.68^{*}$ & 0.20 & 0.43 & 0.29 & -0.69 & 0.57 & 0.75 \\
\hline $\mathrm{P}_{2} \mathrm{O}_{5}$ & 0.11 & $0.64^{*}$ & 0.36 & 0.17 & 0.04 & 0.04 & 0.56 & 0.47 \\
\hline $\mathrm{TiO}_{2}$ & -0.55 & $0.60^{*}$ & 0.01 & 0.39 & -0.66 & 0.85 & -0.06 & 0.70 \\
\hline $\mathrm{MnO}$ & 0.17 & $-0.43^{*}$ & -0.28 & 0.22 & 0.13 & 0.39 & -0.37 & -0.11 \\
\hline
\end{tabular}

Table 4 Original classification results from discriminant function analysis performed using the weight percentages (centered log-ratio transformed) of ten oxides as predictors of region $(\mathrm{CV}=$ Cape Verde Islands, MAR $=$ Mid-African Rift, EAR = East African Rift, RS = Red Sea Rift, HI = Hawaiian Islands; $n=10,553)$. Results reveal $78.4 \%$ of all cases identified correctly (expected hit ratio by chance of $54.4 \%$ )

\begin{tabular}{llllllr}
\hline & CV & MAR & EAR & RS & HI & Total \\
\hline Count & & & & & & \\
CV & 247 & 1 & 58 & 0 & 412 & 718 \\
MAR & 39 & 38 & 80 & 3 & 168 & 328 \\
EAR & 133 & 48 & 1030 & 33 & 682 & 1926 \\
RS & 3 & 1 & 8 & 30 & 37 & 79 \\
HI & 57 & 57 & 369 & 86 & 6933 & 7502 \\
$\%$ & & & & & & \\
CV & 34.4 & 0.1 & 8.1 & 0.0 & 57.4 & 100 \\
MAR & 11.9 & 11.6 & 24.4 & 0.9 & 51.2 & 100 \\
EAR & 6.9 & 2.5 & 53.5 & 1.7 & 35.4 & 100 \\
RS & 3.8 & 1.3 & 10.1 & 38.0 & 46.8 & 100 \\
HI & 0.8 & 0.8 & 4.9 & 1.1 & 92.4 & 100 \\
\hline
\end{tabular}

Italicized location that received highest percent classification Note that all African regions, except the East African Rift, are misclassified as the Hawaiian Islands

alkalinity, our TAS diagram also supports a high silica content for Group 2. This is confirmed by principal component 2 and discriminant function 2, which are associated with $\mathrm{Si}$ and $\mathrm{Al}$. This particular geochemical
Table 5 Mean discriminant score for each region by discriminant function from discriminant function analysis performed using the weight percentages (centered log-ratio transformed) of ten oxides as predictors of region ( $\mathrm{CV}=$ Cape Verde Islands, MAR = Mid-African Rift, EAR = East African Rift, RS = Red Sea Rift, HI = Hawaiian Islands; $n=10,553$ )

\begin{tabular}{lrrrr}
\hline & DF 1 & \multicolumn{1}{c}{ DF 2 } & \multicolumn{1}{c}{ DF 3 } & \multicolumn{1}{c}{ DF 4 } \\
\hline CV & 0.54 & 1.58 & -0.05 & -0.30 \\
MAR & 1.34 & 0.60 & 0.91 & 0.53 \\
EAR & 1.73 & -0.34 & -0.14 & 0.00 \\
RS & 0.19 & -2.01 & 1.36 & -1.54 \\
HI & -0.56 & -0.07 & -0.01 & 0.02 \\
\hline
\end{tabular}

combination, high alkalinity and high silica content, is atypical among volcanic compositions. Alkaline igneous rocks make up only about $1 \%$ of all rocks worldwide, and of these, most are silica-depleted (Fitton and Upton 1987). This unique geochemistry of bedrock implies a unique suite of minerals which, with time and local weathering conditions, will lead to a unique soil. We propose that the composition of bedrock identified by Group 2, when weathered, leads to the production of elemental subcomponents that may play a role in the onset of podoconiosis.

Principal component 1 and discriminant function 1 : Enrichment in incompatible elements is unique to Group 2 and may provide a significant 

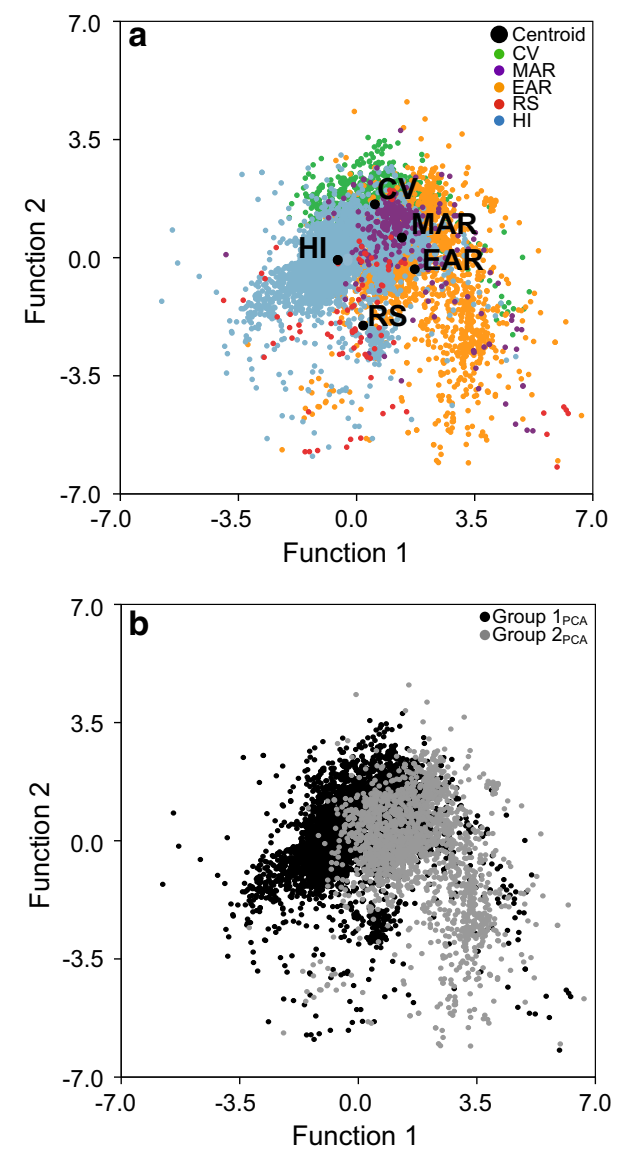

Fig. 9 Discriminant function scores on functions 1 and 2 (centered log-ratio transformed data $[n=10,553]$ ) color coded to show a five regions $(\mathrm{CV}=$ Cape Verde Islands, MAR $=$ MidAfrican Rift, EAR = East African Rift, RS = Red Sea Rift, $\mathrm{HI}=$ Hawaiian Islands) and $\mathbf{b}$ Group $1_{\mathrm{PCA}}$ and Group $2_{\mathrm{PCA}}$

geochemical clue for determining the nature of the "irritant particles."

The separation of cases along principal component 1 in Fig. 5 and along discriminant function 1 in Fig. 9 is associated with relative abundances of $\mathrm{Mg}, \mathrm{Ca}, \mathrm{Na}$, and K. In standard igneous petrology, the terms compatible and incompatible describe the behavior of elements within the magma melt system and their affinity for staying in the solid or concentrating into the liquid magma, respectively. This process controls both major and trace element distribution in the rocks and is indicative of the amount of magma differentiation. Relative amounts of $\mathrm{Mg}, \mathrm{Ca}, \mathrm{Na}$, and $\mathrm{K}$ are commonly used to characterize a highly evolved magma from its more primitive progenitor (Ragland
Table 6 Pairwise comparisons of distance between group centroids in discriminant function space defined by all four discriminant functions for the five regions $(\mathrm{CV}=$ Cape Verde Islands, MAR = Mid-African Rift, EAR = East African Rift, RS = Red Sea Rift, HI = Hawaiian Islands; $n=10,553$ )

\begin{tabular}{ccccc}
\hline & EAR & HI & MAR & RS \\
\hline CV & & & & \\
$F$ & 271.08 & 263.82 & 72.23 & 117.82 \\
$p$ & $<0.001$ & $<0.001$ & $<0.001$ & $<0.001$ \\
EAR & & & \\
$F$ & & 610.73 & 67.10 & 74.00 \\
$p$ & $<0.001$ & $<0.001$ & $<0.001$ \\
HI & & & \\
$F$ & & 161.90 & 67.76 \\
$p$ & & $<0.001$ & $<0.001$ \\
MAR & & & & 80.24 \\
$F$ & & & $<0.001$ \\
$p$ & & & \\
\hline
\end{tabular}

The largest separation is between the Hawaiian Island and East African Rift centroids

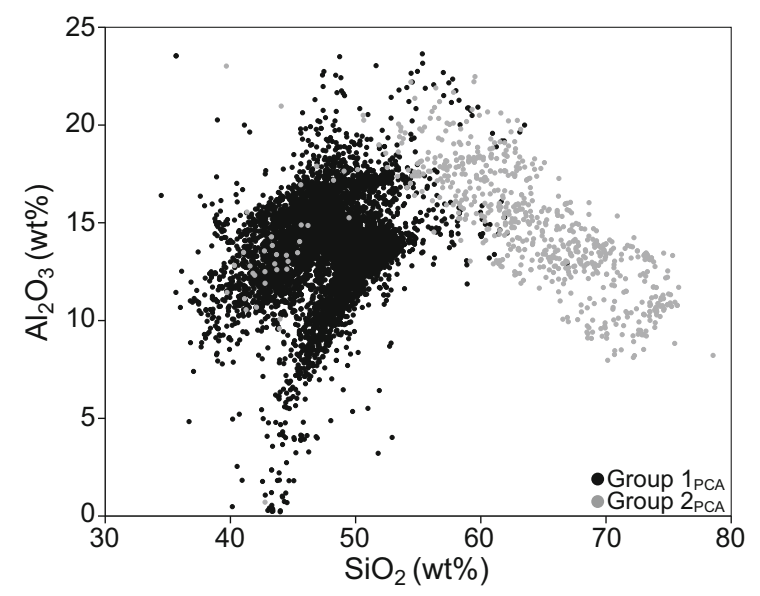

Fig. 10 Harker diagram of $\mathrm{SiO}_{2}$ vs. $\mathrm{Al}_{2} \mathrm{O}_{3}(n=10,553)$ for Group $1_{\mathrm{PCA}}$ and Group $22_{\mathrm{PCA}}$ using a untransformed weight percent and $\mathbf{b}$ centered log-ratio transformed weight percent

1989; Rollinson 1993). Mg and Ca are compatible, whereas $\mathrm{K}$ and $\mathrm{Na}$ are incompatible. Interpretation of PCA and DFA results indicates that Group 2 cases are characterized by greater relative abundances of incompatible elements compared to Group 1 cases. Because principal component 1 has large positive loadings from $\mathrm{Mg}$ and $\mathrm{Ca}$ and large negative loadings from $\mathrm{K}$ and $\mathrm{Na}$ (Fig. 4), the relatively lower scores of 
Group 2 on component 1 (Fig. 5) indicate lower relative abundances of $\mathrm{Mg}$ and $\mathrm{Ca}$ and higher relative abundances of $\mathrm{K}$ and $\mathrm{Na}$ in comparison with Group 1 . Likewise, because discriminant function 1 has substantial negative structure matrix correlations with $\mathrm{Mg}$ and $\mathrm{Ca}$ and substantial positive correlations with $\mathrm{K}$ and $\mathrm{Na}$ (Table 3), the relatively higher scores of Group 2 on function 1 (Fig. 9) also indicate lower relative abundances of $\mathrm{Mg}$ and $\mathrm{Ca}$ and higher relative abundances of $\mathrm{K}$ and $\mathrm{Na}$ in comparison with Group 1. This link with incompatible elements is supported by the results of local soil research by Le Blond et al. (2017) who also report an increase in $\mathrm{K}$ and $\mathrm{Na}$ in endemic soils.

Alternatively, the cause of podoconiosis may not be enrichment in major incompatible elements (or their associated minerals), but rather trace elements associated with them. Some podoconiosis literature has mentioned the presence of trace elements, specifically $\mathrm{Be}, \mathrm{Ce}, \mathrm{Co}, \mathrm{Cr}, \mathrm{Cu}, \mathrm{La}, \mathrm{Nd}, \mathrm{Ni}, \mathrm{S}, \mathrm{Sn}, \mathrm{V}, \mathrm{Zn}$, and $\mathrm{Zr}$ (Price and Pitwell 1973; Price and Henderson 1978; Frommel et al. 1993). Frommel and his colleagues argue strongly that $\mathrm{Be}$ and $\mathrm{Zr}$ are of particular interest due to the elevated levels of these elements they found in soils associated with podoconiosis, along with the ability of both to form granular masses within the body. Certain trace elements follow similar substitution patterns to those of the major elements within melt systems. For instance, the large ion lithophile (LIL) elements $\mathrm{Rb}$ and $\mathrm{Cs}$ can substitute for the elements $\mathrm{Na}$ and $\mathrm{K}$, the incompatible elements identified as important in Group 2 (Rollinson 1993). In contrast, Frommel et al. (1993) reported elevated levels of $\mathrm{Ba}$ and $\mathrm{Sr}$ in soils from towns where podoconiosis is not present. This supports our hypothesis as these trace elements could follow the trends of compatible elements (Rollinson 1993). We hypothesize that specific trace elements predicted by the presence of incompatible major elements may play a role in the etiology of podoconiosis. Recent soil research has reported higher levels of $\mathrm{Cr}, \mathrm{Ni}, \mathrm{Si}, \mathrm{Y}$, and $\mathrm{Zr}$ within endemic soils (Molla et al. 2014; Le Blond et al. 2017). Future work that focuses on tracking the pathway of the trace elements enriched in Group 2 to the podoconiosis-associated soils may be key to the etiology of podoconiosis.

Principal component 2 and discriminant function 2:

Silica and alumina are responsible for minimal separation between Group 1 and Group 2, and their role in podoconiosis may be less significant than previous literature suggests.

Silica is often named alone, or in combination with aluminum, as the "irritant particle" in podoconiosis literature (Heather and Price 1972; Price and Pitwell 1973; Price and Henderson 1979; Price and Bailey 1984; Fyfe and Price 1985; Price 1988; Frommel et al. 1993). Our analyses reveal principal component 2 and discriminant function 2 are associated with $\mathrm{Si}$ and $\mathrm{Al}$ (Fig. 4, Table 3). The geochemical behavior of Si and Al is slightly different than that of the compatible/ incompatible elements due to their high abundance in the crust. Higher relative amounts of $\mathrm{Si}$ and $\mathrm{Al}$ are frequently correlated with magma at relatively shallow levels in the crust (Rollinson 1993; Best and Christiansen 2001). In addition to the major role that rifting plays in the African regions, plume effects are also present to varying degrees (Déruelle et al. 1991; Anderson and Schramm 2005; Furman et al. 2006). Since plumes originate from deeper sources, their magma contains relatively low amounts of silica. Thus, the greater the effect of rift volcanics, the higher the silica; the greater the effect of plume volcanics, the lower the silica. Results from our AFM, TAS, PCA, and DFA (Figs. 2a, 3a, 5a, 9a) frequently found the Cape Verde Islands and the Red Sea Rift showing more similar geochemistry to that of the Hawaiian Islands than we expected. We attribute this similarity to the higher proportion of plume volcanics associated with their formation than of the other regions (Anderson and Schramm 2005; Furman et al. 2006; Ramalho 2011).

A comment needs to be made about the unexpected loading of Mn near Si and $\mathrm{Al}$ on principal component 2 as $\mathrm{Mn}$ is a compatible element and normally follows the same magmatic evolution patterns to that of $\mathrm{Mg}$ or Fe. We believe the observed loading is influenced by Hawaiian cases and follows from the inclusion of dacite melts with picritic melts in the Hawaiian lavas as suggested by Huang et al. (2007).

Some differences in the relative abundances of $\mathrm{Si}$ and $\mathrm{Al}$ among the five regions can be estimated upon visual inspection of both the principal component scores and discriminant function scores plots (Figs. 5a, 9a), as component/function 2 are associated with Si and Al. The Cape Verde Islands and MidAfrican Rift tend to plot lower on component 2 and 
higher on function 2, indicating relatively lower silica and aluminum, than the East African Rift and the Hawaiian Islands. However, a subtler separation along component/function 2 is visible when comparing plots coded by Group. Though Groups 1 and 2 show similar ranges along both component 2 and function 2 , mean values for the Groups are different on both. These results indicate a relatively higher silicon and aluminum content for Group 2, whose geochemistry we propose is associated with podoconiosis. However, Cohen's $d$ for the comparison of Group 1 and 2 on both component 2 and function 2 is approximately half that for component 1 and function 1, suggesting that the importance of component/function 2, and thus $\mathrm{Si}$ and $\mathrm{Al}$, is relatively minimal. Le Blond et al. (2017) report a significant difference in mean values for both $\mathrm{Si}$ and Al between endemic and nonendemic soils. This difference between bedrock and soil geochemistry might suggest enrichment due to weathering or anthropological activities.

Another line of research has suggested that it is not merely the presence of silicon and/or aluminum in soils, but their ratio that is of importance to podoconiosis. Several studies (Heather and Price 1972; Price and Henderson 1978, 1979; Price et al. 1981; Blundell et al. 1989) analyzed particles found in the lymph nodes of individuals affected by and not affected by podoconiosis. These studies found no difference in the number of particles between affected and unaffected individuals. However, a statistically significant difference in the silicon:aluminum ratio was reported and suggested to be of importance to the disease process. As a preliminary investigation of this hypothesis, we tested for a difference in the $\mathrm{SiO}_{2}: \mathrm{Al}_{2} \mathrm{O}_{3}$ ratio among the five regions with no clear results. The Mid-African Rift, East African Rift, and Red Sea Rift do have higher mean ratios than does the Hawaiian Islands. However, the Cape Verde Islands mean is lower than that of Hawaii, so there is no clear separation of the podoconiosis-associated regions from non-associated region. When considered in terms of Groups, we found Group 2 had a significantly larger $\mathrm{SiO}_{2}: \mathrm{Al}_{2} \mathrm{O}_{3}$ ratio than that of Group 1, suggesting a higher ratio in areas we propose is associated with podoconiosis. However, the ubiquitous nature of silicon and aluminum, when considered both independently or in association with each other, around the world with no widespread prevalence of podoconiosis (despite the lack of shoes in many countries) is by far the greatest challenge to this theory based on composition alone.

Acknowledgements This paper benefitted from review by William K. Hayes and Torrey Nyborg.

Open Access This article is distributed under the terms of the Creative Commons Attribution 4.0 International License (http:// creativecommons.org/licenses/by/4.0/), which permits unrestricted use, distribution, and reproduction in any medium, provided you give appropriate credit to the original author(s) and the source, provide a link to the Creative Commons license, and indicate if changes were made.

\section{References}

Aitchison, J. (1986). The statistical analysis of compositional data. New York: Chapman and Hall.

Anderson, D. L., \& Schramm, K. A. (2005). Global hotspot maps. Geological Society of America Special Papers, 388, 19-29.

Best, M. G., \& Christiansen, E. H. (2001). Igneous Petrology. Malden, MA: Blackwell Science Inc.

Bisani, M. L., Faraone, D., Clementi, S., Esbensen, K. H., \& Wold, S. (1983). Principal components and partial leastsquares analysis of the geochemistry of volcanic-rocks from the Aeolian Archipelago. Analytica Chimica Acta, 150(1), 129-143. https://doi.org/10.1016/s00032670(00)85465-3.

Blundell, G., Henderson, W. J., \& Price, E. W. (1989). Soil particles in the tissues of the foot in endemic elephantiasis of the lower legs. Annals of Tropical Medicine and Parasitology, 83(4), 381-385.

Clark, M. (1948). Lymphostatic verrucosis in the Fort Hall District of Kenya. Transactions of the Royal Society of Tropical Medicine and Hygiene, 42(3), 287-290.

Cohen, L. B. (1960). Idiopathic lymphoedema of Ethiopia and Kenya. East African Medical Journal, 37, 53-74.

Cohen, J. (1988). Statistical power analysis for the behavioral sciences. Hillsdale, NJ: Routledge.

Corachan, M., Tura, J. M., Campo, E., Soley, M., \& Traveria, A. (1988). Podoconiosis in Equatorial Guinea: Report of two cases from different geological environments. Tropical and Geographical Medicine, 40(4), 359-364.

Deribe, K., Brooker, S. J., Pullan, R. L., Hailu, A., Enquselassie, F., Reithinger, R., et al. (2013). Spatial distribution of podoconiosis in relation to environmental factors in Ethiopia: A historical review. PLoS One, 8(7), 8. https:// doi.org/10.1371/journal.pone.0068330.

Deribe, K., Cano, J., Giorgi, E., Pigott, D. M., Golding, N., \& Pullan, R. L., et al. (2017). Estimating the number of cases of podoconiosis in Ethiopia using geostatistical methods. In Wellcome open research, 2.

Deribe, K., Cano, J., Newport, M. J., Golding, N., Pullan, R. L., Sime, H., et al. (2015). Mapping and modelling the geographical distribution and environmental limits of 
podoconiosis in Ethiopia. Tropical Medicine and International Health, 20, 39-40.

Déruelle, B., Moreau, C., Nkoumbou, C., Kambou, R., Lissom, J., \& Njonfang, E., et al. (1991). The Cameroon line: a review. In Magmatism in extensional structural settings (pp. 274-327): Springer, New York.

Fitton, J. G. (1987). The Cameroon line, west Africa: A comparison between oceanic and continental alkaline volcanism. In J. G. Fitton \& B. G. J. Upton (Eds.), Alkaline igneous rocks (Vol. 30, pp. 273-291). Oxford: Geological Society Special Publication, Blackwell Scientific Publications.

Fitton, J. G., \& Upton, B. G. J. (1987). Introduction. In J. G. Fitton \& B. G. J. Upton (Eds.), Alkaline igneous rocks (Vol. 30, pp. 9-14). Oxford: Geological Society Special Publication, Blackwell Scientific Publications.

Frommel, D., Ayranci, B., Pfeifer, H. R., Sanchez, A., Frommel, A., \& Mengistu, G. (1993). Podoconiosis in the Ethiopian rift-valley: Role of beryllium and zirconium. Tropical and Geographical Medicine, 45(4), 165-167.

Furman, T., Bryce, J., Rooney, T., Hanan, B., Yirgu, G., \& Ayalew, D. (2006). Heads and tails: 30 million years of the Afar plume. Geological Society, 259(1), 95-119.

Fyfe, N. C. M., \& Price, E. W. (1985). The effects of silica on lymph-nodes and vessels: A possible mechanism in the pathogenesis of non-filarial endemic elephantiasis. Transactions of the Royal Society of Tropical Medicine and Hygiene, 79(5), 645-651.

Green, S. B., \& Salkind, N. J. (2005). Using SPSS for Windows and Macintosh (4th ed.). Upper Saddle River: Pearson.

Grunsky, E. C. (2010). The interpretation of geochemical survey data. Geochemistry-Exploration Environment Analysis, 10(1), 27-74. https://doi.org/10.1144/1467-7873/09-210.

Grunsky, E. C., Easton, R. M., Thurston, P. C., \& Jensen, L. S. (1992). Characterization and statistical classifications of archean volcanic rocks of the superior province using major element geochemistry. (Vol. 4, pp. 1397-1438). Toronto, Canada: Ontario Geological Survey.

Heather, C. J., \& Price, E. W. (1972). Non-filarial elephantiasis in Ethiopia analytical study of inorganic material in lymph-nodes. Transactions of the Royal Society of Tropical Medicine and Hygiene, 66(3), 450.

Hojat, M., \& Xu, G. (2004). A visitor's guide to effect sizesStatistical significance versus practical (clinical) importance of research findings. Advances in Health Sciences Education, 9(3), 241-249. https://doi.org/10.1023/B: AHSE.0000038173.00909.f6.

Huang, S. C., Humayun, M., \& Frey, F. A. (2007). Iron/manganese ratio and manganese content in shield lavas from Ko'olau Volcano, Hawai'i. Geochimica Et Cosmochimica Acta, 71(18), 4557-4569. https://doi.org/10.1016/j.gca. 2007.07.013.

Jordan, P., Trant, M. H., \& Laurie, W. (1956). Non-Bancroftian elephantiasis in Tanganyika. British Medical Journal, l(JAN28), 209-210.

Kampunzu, A., \& Mohr, P. (1991). Magmatic evolution and petrogenesis in the East African rift system. In A. Kampunzu \& R. T. Lubala (Eds.), Magmatism in extensional structural settings (pp. 85-136). New York, NY: Springer.

Kampunzu, A., \& Popoff, M. (1991). Distribution of the main Phanerozoic African rifts and associated magmatism: introductory notes. In A. B. Kampunzu \& R. T. Lubala (Eds.), Magmatism in extensional structural settings (pp. 2-10). New York, NY: Springer.

Kirch, P. V. (1997). Feathered gods and fishhooks: An introduction to Hawaiian archaeology and prehistory. Honolulu, HI: University of Hawaii Press.

Kirch, P. V., \& Zimmerer, K. S. (2011). Roots of Conflict: soils, agriculture, and sociopolitical complexity (School for Advanced Research Advanced Seminar Series). Santa Fe, NM: SAR Press.

Kovacs, L. O., \& Kovacs, G. P. (2001). Petrochemical database of the Cenozoic volcanites in Hungary: structure and statistics. Acta Geologica Hungarica, 44(4), 381-417.

Le Blond, J. S., Baxter, P. J., Bello, D., Raftis, J., Molla, Y. B., Cuadros, J., et al. (2017). Haemolytic activity of soil from areas of varying podoconiosis endemicity in Ethiopia. PLoS One, 12(5), e0177219.

Le Maitre, R. W. (1976). A new approach to the classification of igneous rocks using the basalt-andesite-dacite-rhyolite suite as an example. Contributions to Mineralogy and Petrology, 56, 191-203.

Le Maitre, R. W., Streckeisen, A., Zanettin, B., Le Bas, M. J., Bonin, B., Bateman, P., et al. (2002). Igneous rocks: a classification and glossary of terms (2nd ed.). Cambridge: Cambridge University Press.

Loewenthal, L. J. A. (1934). On the probable inclusion of several diseases in the title " Mossy" Foot'. Annals of Tropical Medicine and Parasitology, 28(1), 47-62. https://doi. org/10.1080/00034983.1934.11684787.

Mertler, C. A., \& Vannatta, R. A. (2005). Advanced and multivariate statistical methods (3rd ed.). Glendale, CA: Pyrczak Publishing.

Molla, Y. B., Wardrop, N. A., Le Blond, J. S., Baxter, P., Newport, M. J., Atkinson, P. M., et al. (2014). Modelling environmental factors correlated with podoconiosis: a geospatial study of non-filarial elephantiasis. International Journal of Health Geographics, 13, 12. https://doi.org/10. 1186/1476-072x-13-24.

Nakagawa, S. (2004). A farewell to Bonferroni: The problems of low statistical power and publication bias. Behavioral Ecology, 15(6), 1044-1045. https://doi.org/10.1093/ beheco/arh107.

Nakagawa, S., \& Cuthill, I. C. (2007). Effect size, confidence interval and statistical significance: a practical guide for biologists. Biological Reviews, 82(4), 591-605. https://doi. org/10.1111/j.1469-185X.2007.00027.x.

Oomen, A. P. (1969). Studies on elephantiasis of legs in Ethiopia. Tropical and Geographical Medicine, 21(3), 236-253.

Pawlowsky-Glahn, V., \& Egozcue, J. J. (2012). Compositional data and their analysis: an introduction. In A. Buccianti, G. Mateu-Figueras, \& V. Pawlowsky-Glahn (Eds.), Compositional data analysis in the geosciences: From theory to practice (Vol. 264, pp. 1-10). London: Geological Society of London.

Pearce, J. A. (1976). Statistical analysis of major element patterns in basalts. Journal of Petrology, 17(1), 15-43.

Price, E. W. (1974a). Endemic elephantiasis of the lower legs in Ethiopia. An epidemiological survey. Ethiopian Medical Journal, 12(2), 77-90. 
Price, E. W. (1974b). The relationship between endemic elephantiasis of lower legs and local soils and climate: Study in Wollamo district, Southern Ethiopia. Tropical and Geographical Medicine, 26(3), 225-230.

Price, E. W. (1975). The mechanism of lymphatic obstruction in endemic elephantiasis of lower legs. Transactions of the Royal Society of Tropical Medicine and Hygiene, 69(2), 177-180. https://doi.org/10.1016/0035-9203(75)90150-9.

Price, E. W. (1976). Association of endemic elephantiasis of lower legs in East-Africa with soil derived from volcanic rocks. Transactions of the Royal Society of Tropical Medicine and Hygiene, 70(4), 288-295.

Price, E. W. (1988). Non-filarial elephantiasis_confirmed as a geochemical disease, and renamed podoconiosis. Ethiopian Medical Journal, 26(3), 151-153.

Price, E. W. (1990). Podoconiosis: Non-filarial elephantiasis. New York: (Oxford medical publications) Oxford University Press.

Price, E. W., \& Bailey, D. (1984). Environmental factors in the etiology of endemic elephantiasis of the lower legs in tropical Africa. Tropical and Geographical Medicine, 36(1), 1-5.

Price, E. W., \& Henderson, W. J. (1978). Elemental content of lymphatic tissues of barefooted people in Ethiopia, with reference to endemic elephantiasis of lower legs. Transactions of the Royal Society of Tropical Medicine and Hygiene, 72(2), 132-136.

Price, E. W., \& Henderson, W. J. (1979). Silica and silicates in femoral lymph-nodes of barefooted people in Ethiopia with special reference to elephantiasis of the lower legs. Transactions of the Royal Society of Tropical Medicine and
Hygiene, 73(6), 640-647. https://doi.org/10.1016/00359203(79)90011-7.

Price, E. W., \& Henderson, W. J. (1981). Endemic elephantiasis of the lower legs in the United-Cameroon-Republic. Tropical and Geographical Medicine, 33(1), 23-29.

Price, E. W., McHardy, W. J., \& Pooley, F. D. (1981). Endemic elephantiasis of the lower legs as a health hazard of barefooted agriculturalists in Cameroon, West Africa. Annals of Occupational Hygiene, 24(1), 1-8.

Price, E. W., \& Pitwell, L. R. (1973). The mineral content of inguinal nodes in barefoot people with and without elephantiasis of the legs. Journal of Tropical Medicine Hygiene, 76(9), 236-238.

Ragland, P. C. (1989). Basic analytical petrology. New York, NY: Oxford University Press.

Ragland, P. C., Conley, J. F., Parker, W. C., \& VanOrman, J. A. (1997). Use of principal components analysis in petrology: An example from the Martinsville Igneous Complex, Virginia, USA. Mineralogy and Petrology, 60(3-4), 165-184. https://doi.org/10.1007/bf01173708.

Ramalho, R. A. (2011). Building the cape verde Islands (Springer Theses). New York, NY: Springer.

Rollinson, H. R. (1993). Using geochemical data: evaluation, presentation, interpretation (Geochemistry series). New York, NY: Longman Scientific and Technical.

Ruiz, L., Campo, E., \& Corachan, M. (1994). Elephantiasis in Sao-Tome and Principe. Acta Tropica, 57(1), 29-34.

Schlüter, T. (2006). Geological atlas of Africa: With notes on stratigraphy, tectonics, economic geology, geohazards and geosites of each country. Heidelberg: Springer.

White, R. E. (2013). Principles and practice of soil science: the soil as a natural resource. Hoboken: Wiley. 